\title{
CARTOGRAFIAS PARA A FICÇÃO CIENTÍFICA MUNDIAL: CINEMA E LITERATURA. ALFREDO SUPPIA (ORG.). 2015
}

Pedro Sasse (UERJ)

Recebido em 05 fev 2018. Pedro Sasse é Doutorando em Estudos de Literatura Aprovado em 14 mai 2018. pela UFF e mestre em Teoria da Literatura e Literatura Comparada pela UERJ. Atualmente desenvolve o projeto "Expressões do medo: crime, literatura e cultura no Brasil". É professor substituto da Faculdade de Formação de Professores da UERJ. E-mail: pedro_ sasse@hotmail.com 
Dado os eventos recentes da premiação do Oscar a um filme de ficção científica (doravante FC), A forma da água (2018), de Guillermo Del Toro, e do Nobel a um autor que escreve FC, Kazuo Ishiguro, em 2017, é visível a importância desse gênero hoje. Na academia, da mesma forma, a FC vem ganhando cada vez mais espaço, com dezenas de dissertações e teses apenas nos últimos anos. Nesse contexto, obras como

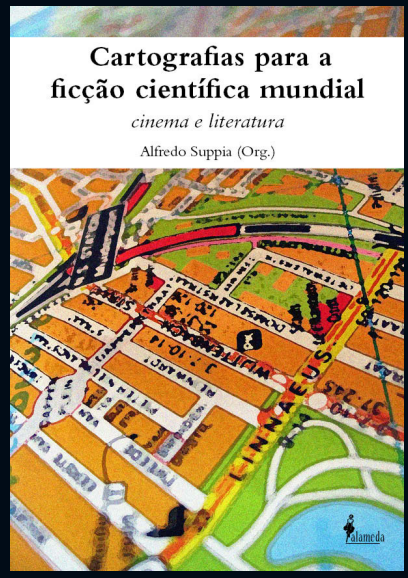
Cartografias para a FC mundial se tornam cruciais para fornecer de um rico fundamento teórico e crítico pesquisadores que desejem iniciar ou prosseguir nesse rumo hoje.

Alfredo Suppia, professor do Departamento de Cinema e do Programa de Pós-Graduação em Multimeios da UNICAMP, e pesquisador veterano do gênero - contando com publicações na área como Metrópole replicante: construindo um diálogo entre Metropolis e Blade Runner (2011) e Atmosfera rarefeita: a ficção científica no cinema brasileiro (2013) -, é organizador do livro, que reúne pesquisadores internacionais e nacionais de renome na área.

O livro é dividido em duas partes. Os oito primeiros artigos são dedicados à FC fora da América Latina, mas sem concentrar-se apenas na produção hegemônica: abordam obras do leste europeu, da antiga República Democrática Alemã e até uma coprodução entre Polônia e Japão. Já o segundo bloco é voltado exclusivamente para a produção latino-americana, contando com panoramas históricos aprofundados sobre a produção de países como Argentina, México 
e, claro, o próprio Brasil, além de textos críticos que exploram casos de interesse específico.

Com intuito de suprir uma carência bibliográfica em língua portuguesa na área dos estudos de FC, o livro não conta apenas com material original, mas também oferece artigos publicados anteriormente em alguns dos mais prestigiados periódicos acadêmicos especializados no gênero. Com isso, a obra pretendese, como seu título diz, uma cartografia da FC, ou seja, um mapa introdutório que mostre alguns dos muitos caminhos possíveis a se percorrer nos estudos desse gênero tão rico em possibilidades e tão central para a cultura do século XXI.

Para abrir o livro, foi escolhido o artigo "Ansiedade digital e o novo cinema verité de horror e ficção científica", de Barry Keith Grant, que abordará um fenômeno que ganhou força nos últimos anos, mas cujas origens, como mostrará Grant, se encontram ainda no século XIX: obras de baixo custo de produção, filmadas a partir de uma câmera de mão (ou câmeras de segurança, celulares etc.) e que mascaram sua ficcionalidade normalmente com aparência de um documentário real, chamadas popularmente de found footages.

Tendo em vista que o found footage é um conceito aplicado apenas a um tipo específico de moldura dentro de uma vertente mais heterogênea, Grant optará pelo conceito de cinema verité, identificando como predecessor o teatro Grand Guignol francês e marcando como pioneiros do gênero Holocausto Canibal (1980), de Ruggero Deodato, e o belga Aconteceu perto de sua casa (1992), de Benoît Poelvoorde, Rémy Belvaux e André Bonzel. 
Para Grant, a popularização desse tipo de filme, que funde com frequência horror e $\mathrm{FC}$, e faz com que o espectador se identifique mais com a própria câmera que com os personagens da história, reflete certa ansiedade "pós-moderna acerca da verdade indexadora da imagem que foi exacerbada pela ubiquidade da tecnologia digital" (p.20). Jogando, assim, com as fronteiras entre real e ficcional, dentro das convenções do documental, o cinema verité expõe como o valor de verdade da imagem, sobretudo do vídeo, vem se degradando.

O autor não se limita ao histórico e à reflexão sobre o gênero na contemporaneidade, mas tece seus comentários sobre uma ampla gama de narrativas que dialogam com essa vertente, desde influências de pseudodocumentários como The War Game (1965), de Peter Watkins, a desdobramentos do cinema verité nos jogos digitais, com o Survival Horror, passando por clássicos da vertente como A bruxa de Blair (1999), Eduardo Sánchez e Daniel Myrick, e o espanhol [REC] (2007), de Paco Plaza e Jaume Balagueró. Com isso, temos um claro exemplo de como a própria forma de narrar pode ser alterada através das relações entre a tecnologia e o homem, seja para representar seus anseios, seja para representar seus medos, seja para jogar com seus sentidos na contemporaneidade.

Se a FC tem a capacidade de condensar certo zeitgeist contemporâneo e deslocá-lo para um futuro hipotético, vemos no artigo "A Pátria-Terra e o Outro: 2001, Solaris e Eolomea em diálogo", de Sonja Fritzsche, o quão rica pode ser uma leitura que leve em conta esse aspecto. 
Nele, Fritzsche mostra como o contexto da guerra-fria dialogou intensamente com a produção cinematográfica de FC através de filmes representativos dos polos desse conflito - o americano 2001: uma odisseia no espaço (1968), de Stanley Kubrik, e o soviético Solaris (1972), de Andrei Tarkovsky, ambos contrastados com o foco de seu artigo, Eolomea (1972), de Hermann Zschoche, produzido na República Democrática Alemã (RDA).

Todas as obras partem de um mesmo questionamento crucial para a época: diante de todos os avanços tecnológicos - e as tensões políticas e sociais que os acompanharam - o que significa ser humano no planeta Terra?

Longe de manter o constante otimismo utópico defendido por certo modo comunista de pensar a arte - que serviria de modelo e incentivo ao proletariado -, Eolomea projetaria o ideal de um futuro socialista, mas, ao mesmo tempo, questionaria o modelo marxista-leninista através das tensões entre novo/velho, humano/ natureza, Terra/espaço e indivíduo/comunidade, se afastando do padrão de Solaris. Da mesma forma, ao abordar esse futuro de um modo mais crítico, Zschoche se afasta da celebração sublime do progresso humano de Kubrik, buscando uma exploração espacial mais banalizada, tediosa, mais humana.

Segundo a autora, a própria noção de progresso perde força em Eolomea: o futuro comunista já foi alcançado. Eolomea, que significa "Primavera", é uma narrativa menos sobre desenvolvimentos que sobre mudanças, é uma celebração de um novo começo, não do ápice de um processo passado.

Enquanto nos filmes explorados por Frizsche, a exploração espacial serve de ponto de partida para a exaltação dos avanços 
tecnológicos e do poder da ciência - ainda que com suas devidas críticas -, Lúcio Piedade, em "No espaço ninguém pode ouvir seus gritos: ficção científica, horror e viagens interplanetárias", trabalhará o lado obscuro e verdadeiramente aterrorizante do espaço sideral.

Por mais que, em maior ou menor grau, já seja possível ver ecos das ansiedades sobre os perigos do espaço em obras como Solaris ou 2001, os medos do desconhecido espacial serão plenamente explorados no horror espacial, gênero trabalhado por Lúcio Piedade no artigo. O autor estabelece as raízes do gênero ainda no horror cósmico lovecraftiano, que já flertava com as ameaças trazidas por civilizações extraterrestres em sua vasta mitologia.

Para, Lúcio, é, contudo, o famoso episódio da transmissão de Guerra dos mundos (1898) nas rádios da costa leste dos EUA que marca o início de uma longa relação entre o público e o medo das invasões extraterrestres. Se o livro, em si, já é uma mostra de que o tema remonta ao fim do século XIX, seu impacto na sociedade americana da década de 40 prenunciava o começo da era de ouro do horror espacial que se iniciaria anos mais tarde, com uma versão cinematográfica homônima da própria obra de Wells em 1953.

Nesse primeiro ciclo do gênero, que começa em meados dos anos 50 e se estende até os anos 60, Lúcio destaca a importância de filmes como It! The Terror from Beyond the Space (1958), de Edward L. Cahn - um precursor de Alien, o oitavo passageiro (1979), mantendo a mesma estrutura de criatura assassina no espaço confinado de uma nave - A máscara do demônio (1960), de Mario Bava -, filme que explora os elementos do gótico em que a nave pousada em um planeta estranho assume o papel do castelo mal- 
assombrado e a flora alienígena atualiza os bosques soturnos - e Queen of blood (1966), de Curtis Harrington - em que o topos do vampirismo é deslocado para o espaço.

Para o recorte pós anos 60, Lúcio Piedade opta por analisar três obras, segundo ele, basilares para o horror espacial: o sempre citado Alien, O Oitavo Passageiro, de Ridley Scott, talvez ícone mais representativo do ambiente gótico revestido de viagem espacial; Força sinistra (1985), de Tobe Hooper, que, inspirado no romance Vampiros no espaço (1976), de Colin Wilson, retoma o vampirismo explorado por Queen of blood em uma narrativa que vai da temática da invasão extraterrestre ao apocalipse zumbi; e, por fim, $O$ enigma do horizonte (1997), de Paul Anderson, capaz de misturar elementos do terror religioso do inferno com a exploração de dimensões alternativas através de buracos negros, em uma ambientação definida pelo design de produção como "Tecnomedieval".

Dessa forma, Lúcio mostra como, mesmo após décadas de exploração espacial, o espaço sideral se apresenta ainda como uma incógnita ao ser humano, fonte pródiga de terrores e ambiente recorrente para as narrativas que interseccionam o horror e a FC.

Abandonando a imensidão sublime do espaço e os diversos horrores que emanam desse eterno desconhecido, Lúcio Reis Filho, em "Impermanência entusiasta: A noite dos mortos-vivos e os sangrentos espasmos dos anos 60", mostra como esse zeitgeist da Guerra Fria produziu ameaças bem mais terrenas - ainda que igualmente aterrorizantes. Seguindo a metodologia de encarar a obra como um objeto cultural que permite uma leitura da sociedade que a engendra - abordagem bem popular hoje, e frequentemente 
encontrada ao longo da coletânea -, Lúcio Reis analisa A noite dos mortos vivos (1968), de George Romero, à luz da impermanência entusiasta da juventude da época.

Por impermanência entusiasta, o autor se refere ao momento de efervescência de uma contracultura viva, engajada com movimentos sociais, que floresce nos EUA da época. Através desse confronto com a velha ordem, dessa atitude de desafio aos valores vigentes, o filme se torna transgressor tanto política quanto esteticamente.

Politicamente, a obra de Romero - produzida em um contexto de inquietação social, assassinato de figuras políticas, manifestações de grupos marginalizados, e diante da escalada de guerra do Vietnã - mostra a impotência da política, da mídia, e mesmo da ciência em frear uma horda de, literalmente, consumidores desumanizados. É uma imagem direta de um Estados Unidos que devora a si mesmo.

Une-se ao medo da fragilidade da vida, da ansiedade gerada pela exposição às pilhas de corpos mortos e em decomposição, aquele causado pelos próprios vivos. Como Reis frisa, Ben, negro, sobrevivente da terrível noite, não é morto pelos monstros que povoam a maior parte o filme, mas aqueles que chegam no seu final: a elite branca e armada dos subúrbios americanos.

Reis descreve, ainda, como, em comunhão com a literatura de pioneiros como Matheson em "Eu sou a lenda" (1954), "The shrinking men" (1956) e "A stir of Echoes" (1958), filmes como A noite dos mortos-vivos inaugura o gótico suburbano, mostrando o lado sombrio da aparente utopia representada pela vida isolada e pacífica dos bairros dos subúrbios americanos. Mesmo que longe 
do sangue e da carnificina dos assassinatos políticos internos e da guerra do Vietnã, no gótico suburbano, os segredos sombrios da elite americana vazam e se conformam em monstros que refletem os problemas da própria cultura que os engendrou.

Eva Näripea, em "Queerizando gêneros? De mulheres, homens e alienígenas no cinema de ficção científica do Leste Europeu", venceu o desafio de, dentro de um universo relativamente escasso de obras cinematográficas de FC do leste europeu, encontrar outro tema pouco abordado: representações queer.

Segundo a autora, parte do problema está justamente na visão de que a FC seria assexuada, ou seja, que não caberia a ela discutir papeis de gênero. Isso não só poderia ser visto na escassez de obras que abertamente trabalhariam com o tema, mas também na escassez crítica: apenas em 2009 a Science Fiction Studies fez uma edição explorando questões de sexualidade na FC. No entanto, Näripea ressalta que, contra essa visão de que a FC estaria além dessas questões, há uma vertente crítica que vê no gênero fortes marcas de uma heteronormatividade masculina, mesmo que inconsciente, nos modelos sociais que conformam essas histórias.

Para mostrar um pouco dessa visão, a autora separa três filmes do leste europeu que abordam, de diferentes maneiras, a questão do genérico-sexual em suas tramas: The End of August at the Hotel Ozone (1966), de Jan Schmidt; Dead Mountaineer Hotel (1979), de Grigori Kromanov; e Sexmission (1983), de Juliusz Machulski.

O primeiro a ser analisado é o filme de Schmidt, pertencente ao new age tchecoslovaco. The End of August at the Hotel Ozone narra a história de um futuro pós-apocalíptico em que a maior parte da 
humanidade foi dizimada por uma epidemia de leucemia e pela poluição. Nele, um grupo de mulheres tenta sobreviver enquanto busca sobreviventes, sobretudo homens. Colocando as mulheres em um papel normalmente associado ao gênero masculino - de caçadoras, selvagens, violentas -, o filme discute papeis de gênero, ambição masculina por poder, mas também acaba reafirmando certos valores masculinos ao associar o único personagem homem, dono de uma fazenda, à cultura e à civilidade.

Em Dead Mountaineer Hotel, um sci fi detetivesco realizado na Estônia, vemos uma inversão dos papéis de vítima e monstro típicos do cinema de alienígenas: um grupo de extraterrestres e androides disfarçados na Terra, tendo sido enganados por um grupo terrorista humano, cometem crimes e acabam sendo perseguidos pela polícia. Näripea identifica na forma como a sexualidade dos extraterrestres é apresentada uma maneira velada de o filme abordar questões queer num contexto de proibição soviética.

Por último, em Sexmission, uma distopia em que o gênero masculino é praticamente extinto por um acidente químico, o planeta se reestruturou em uma sociedade plenamente feminina até que dois homens congelados em um experimento criogênico do passado são encontrados e colocam em xeque a sociedade futurista. Nessa obra, em que o governo é controlado por uma Liga Feminista, cujo líder, na verdade, é um homem travestido, não faltam elementos para se mostrar como a heteronormatividade masculina se impõe dentro da FC.

Näripea ainda ressalta como, apesar da posição conservadora que os filmes parecem manter em relação à sexualidade e ao gênero, ainda se mantém a crítica política ao regime soviético, mostrando 
como cada obra pode ter posturas heterogêneas e muitas vezes paradoxais dentro de si.

A Guerra Fria foi um forte motivo para o florescimento de inúmeras obras de FC que abordavam as ansiedades e os medos da época, mas sua queda também trouxe avanços para o gênero, como aborda Ewa Mazierska em "Entre o passado e o futuro, Polônia e Japão: heterotopias de Avalon".

Fruto da primeira e única colaboração entre a Polônia e o Japão após a Guerra Fria, Avalon (2001) se mostra um rico caso de estudo do cinema transnacional, ajudando a refletir como o encontro entre essas duas culturas foi transportado para a ficção e como o público o recebeu. Abordando questões bem próximas às encontradas em The Matrix (1999), dos irmãos Wachowski - e anteriormente no romance Neuromancer (1984) -, Avalon é centrado nas tensões entre a realidade e virtualidade.

Apesar de ter alguns indicativos nacionais, como a língua falada e certos produtos, o filme se passa em um país não nomeado, num futuro em que um jogo de realidade virtual proibido pelo governo chamado Avalon é uma das formas mais populares de entretenimento. A história é focada em Ash, uma jogadora profissional, e sua jornada de descobrimento do mundo virtual de Avalon. Mazierska lê essa obra menos através das óticas mais típicas esperadas nessa temática - como identidade, verdade e simulacro - que por uma perspectiva das relações de Avalon com a política e história recentes da Polônia.

Dessa forma, ressalta aspectos como a curiosa sobreposição de elementos do capitalismo tardio, a modernidade líquida 
baumaniana, e do comunismo tardio, visto nas nuances de um totalitarismo frágil representado pela escassez de comida, filas nas cantinas e comportamentos conspiratórios. A autora faz, ainda, uma leitura das relações entre a guerra e o cinema a partir dos estudos de Paul Virilio, mostrando como o ininterrupto estado de guerra encontrado na realidade virtual dialoga com as teorias do teórico francês.

Por último, as considerações de Mazierska sobre a recepção da obra nos ajudam a ver os entraves que o cinema transnacional pode encontrar, principalmente sendo parte de um gênero como a FC. Desprezado pela crítica polonesa por se afastar dos ideais estéticos e políticos esperados das produções de sua época e negligenciado pela crítica da FC japonesa por ser um filme estrangeiro, Avalon ainda sofre com a competição de grandes produções, como o já citado The Matrix.

Apesar disso, o filme goza de certo prestígio na visão de críticos estrangeiros, que veem em muitos dos elementos criticados pela recepção polonesa justamente os pontos positivos da produção de Oshii. Assim, Marzieska, longe de simplesmente condenar poloneses ou japoneses, mostra a complexidade que um filme transnacional de culturas tão distintas pode alcançar e os obstáculos presentes para uma recepção positiva nos países envolvidos na produção.

Uma vez que o cinema é o assunto central de seis dos oito trabalhos que compõem a primeira parte da coletânea, focada na FC estrangeira, cabe ao artigo "Mundos perdidos e a (anti)utopia na arqueoficção", de Mariano Martín Rodríguez, representar os estudos literários propriamente ditos. 
Seu trabalho recupera uma vertente da FC algo apagada na contemporaneidade: a arqueoficção. Segundo Rodríguez, essa vertente surge após a distopia e as viagens imaginárias, preenchendo, ao lado da FC, o espaço de obras fantásticas que pediam, agora, maior verossimilhança. Enquanto a FC era responsável por projetar esses sonhos científicos para o futuro, a arqueoficção o fazia em um passado utópico.

Chamada de lost-race fiction ou lost world romance, essa vertente centra suas histórias no processo de descoberta e contato do homem civilizado com uma sociedade milagrosamente preservada do progresso humano. Para o autor, a vertente responde a certo anseio gerado pelas descobertas da época, sejam os achados de fauna e flora da paleontologia, sejam as ruínas de civilizações passadas pelas mãos da arqueologia. Durante o apogeu, dezenas de romances exploraram a temática de uma civilização utópica desbravada pelo europeu como King Solomon's Mines (1885) e She (1887), de Haggard, e The Lost World (1912), de Arthur Conan Doyle.

Se por um lado essas histórias veem as civilizações passadas como ambientes utópicos, por outro, persiste um enredo colonialista, no qual a introdução do homem branco nesse cenário será responsável pela destruição daquela sociedade - seja por aculturação ou catástrofe. A partir da Primeira Guerra Mundial, no entanto, Rodríguez nota uma modificação na abordagem de muitos romances desse estilo, que passam a ver as sociedades passadas não como bons selvagens que precisam do progresso, mas como sociedades moralmente evoluídas, que conseguiram se esquivar dos horrores da civilização moderna, como aqueles experimentados na Grande Guerra. 
No entanto, mesmo com a evolução do gênero, Rodríguez percebe que a arqueoficção vem perdendo espaço para a FC de exploração interplanetária, que assume o papel de construir uma antropologia cultural de sociedades imaginadas. Ainda que hoje, dessa forma, não se veja muitos exemplares dessa vertente, o estudo de Rodríguez ajuda a entender que tipo de papel essa ramificação da ficção científica ocupará na história do gênero e que relações estabelece com seus contextos de produção.

"Uma chave para a ficção científica: revisitando o senso do maravilhoso", de Cornel Robu, o último artigo do primeiro bloco, explora o lado teórico do gênero, focando-se nos efeitos causados pela FC. Para o autor, a FC é um dos gêneros mais favorecidos na contemporaneidade para a produção do efeito estético do sublime, que chamará, em seu trabalho, de "senso do maravilhoso".

Seguindo as características do sublime burkeano, Robu enxerga na magnitude um dos elementos centrais para a concretização desse senso do maravilhoso. Ao longo de seu estudo, Robu destacará como essa magnitude pode tomar três formas distintas nos enredos de FC: espacialmente, se divide entre o megacosmos, o universo infinito, que engole o espectador em sua imensidão negra, e o microcosmos, espaço das interações subatômicas, invisíveis e quase indetectáveis; temporalmente, se manifesta na comparação entre a vida efêmera do homem diante da imensidão do tempo geológico ou cósmico, e a nossa percepção do tempo diante da duração infinitesimal dos acontecimentos quânticos. É, no entanto, a magnitude da complexidade a mais capaz de gerar o efeito sublime, que dobra a razão do homem tanto pela vastidão de planetas, raças, culturas e tecnologias que podem ser encontradas 
na imensidão do universo quanto pela complexidade insondável dos paradoxos temporais e dimensões infinitas encontrados em algumas abordagens do espaço-tempo.

O autor faz, ainda, uma crítica ao uso instrumental da FC para fins de alerta, mostrando a necessidade de ter, a priori, a construção de um enredo que explore esse senso do maravilhoso para que dele decorra naturalmente os elementos relacionáveis com uma realidade contextual. Considerando o sublime o efeito definidor da FC, para o autor, mesmo o belo deve estar em uma posição secundária, podendo ser usado, mas não sendo necessário para o bom desenvolvimento do gênero.

Abrindo a segunda metade do livro, dedicada especificamente aos estudos latino-americanos de FC, Rachel Haywood Ferreira faz uma retrospectiva do gênero em "De volta para o futuro: a expansão da ficção latino-americana".

O estudo de Ferreira é voltado para uma descrição da relação entre a crítica e a produção de uma FC independente dos moldes do Norte. Como a autora ressalta, até o começo dos anos 90, 1992 para ser mais exato, não há, na América Latina nenhum movimento crítico sólido que dê conta de estudar a FC. A primeira edição da The Science Fiction Encyclopedia (1972) não apresentava um verbete único para a América Latina, que só aparecia junto à Espanha e Portugal em um parágrafo final de 66 palavras.

Ferreira aponta que, a partir de 1992, não só a própria enciclopédia publica um verbete para a américa-latina, como outras publicações de interesse começam a alavancar os estudos do gênero. O trabalho de Ferreira ao traçar esse panorama é tanto quantitativo 
quanto qualitativo: inicialmente, apresenta, a partir de gráficos, o aumento massivo de obras descobertas ou retrorrotuladas como FC, sobretudo durante o boom da crítica pós 1992.

Para mostrar esse desenvolvimento do gênero e da crítica, seleciona e acompanha o percurso de cinco obras da FC latinoamericana - "Mexico em el año 1970” (1844), de Fósforos-Cerillos; Brasil 2000 (1868-1872), de Joaquim Felício dos Santos; O doutor Benignus (1875), de Augusto Emílio Zaluar; Dos partidos em lucha (1875) e Viaje maravillloso del Señor Nic-nac (1875-76), de Eduardo Ladislao Holmberg -, dividindo esse percurso em três etapas: 1875, época de publicação das obras, normalmente em jornais populares, poucas transformadas em romances, sem atenção da crítica e rapidamente abandonadas pelos próprios autores, que se dedicavam a outros gêneros; 1957, primeira retomada desses pioneiros em algumas reedições - como a compilação dos contos de Holberg e uma tentativa de reedição de Brasil 2000 - o surgimento de editoras especializadas e uma atenção crítica maior, ainda sem a rotulagem de FC; e, por fim, os anos 2000, época em que, graças ao avanço das tecnologias como a digitalização e a internet, foi possível um trabalho colaborativo mundial que, acompanhado das tendências pós-coloniais de estudo de uma literatura de margem, providencia as bases para uma crítica sólida do gênero.

O texto de Ferreira acaba servindo, ainda, de moldura para o artigo "Esboço de uma história da crítica de ficção científica no Brasil", de Roberto de Souza Causo, que aprofundará essa trajetória da crítica focando-se, agora, especificamente no caso brasileiro.

Para tal, Causo parte de nomes já citados por Ferreira, como O Doutor Benignus e Brasil 2000, ampliando a lista de pioneiros 
com "O fim do mundo em 1857" (1857), conto de Joaquim Manuel de Macedo, e "Rui de Leão" (1872), de Machado de Assis, todos no mesmo recorte da segunda metade do século XIX. Assim como Ferreira, Causo toma 1957, ano de lançamento do satélite Sputnik, como marco para a FC no Brasil, com a publicação de obras como Maravilhas da ficção científica (1958), organizado por Fernando Correia da Silva e Wilma Pupo Nogueira Brito; e o romance $O$ homem que viu o disco-voador (1958), de Rubens Teixeira Scavone.

Devido ao contexto posterior às duas guerras e todos os seus horrores, a FC se encontra em um momento privilegiado para pensar as relações da ciência com a sociedade, ganhando críticas positivas mesmo no Brasil. No entanto, como Causo ressalta, o estigma ainda permaneceria em boa parte da crítica tradicional, que via o gênero como comercial e subliterário.

O autor dedica uma parte de seu artigo a uma análise do pioneiro Introdução ao estudo da "Sciente Fiction" (1967), de André Carneiro, um dos maiores nomes da FC no Brasil. Em sua obra, Carneiro não só faz o percurso pelos principais nomes da FC estrangeira, como também aborda casos nacionais, como a Fantastic (1955-60), primeira iniciativa brasileira de uma revista do gênero. Outro importante evento para a crítica da FC no Brasil é a realização do Simpósio de FC no Rio de Janeiro em 1969, dentro da programação do Festival Internacional de Cinema. A publicação do livro com as palestras do evento reunia os mais renomados autores e críticos da FC da época, incluindo o próprio Arthur C. Clarke.

Causo prossegue mostrando como, na década de 80 , com a popularização crescente da FC no Brasil, o gênero começou a despertar interesse acadêmico. Dessa forma, diversas publicações 
introdutórias à FC foram produzidas nessa época, como Ficção científica: ficção, ciência ou uma épica da época? (1985), de Raul Fiker, O que é ficção científica (1985), de Bráulio Tavares, e Introdução a uma história da ficção científica (1987), de Léo Godoy Otero, dos quais só o último dedica certo espaço ao gênero em território brasileiro. Segundo Causo, nessa época houve, ainda, uma profusão de obras que contavam com a colaboração, se não plena autoria, de pesquisadores não profissionais: autores, fãs, jornalistas interessados etc. Apesar do ganho em volume de publicações produzido por esses autores não especializados, muitos críticos, como o próprio André Carneiro, viram com maus olhos essa intromissão nas reflexões sobre o gênero, acusando-os de carecer da erudição encontrada na crítica tradicional.

O autor dedica-se, também, à aparição dos estudos de FC especificamente no âmbito acadêmico, em que menciona como obra pioneira A ficção do tempo: análise da narrativa de Science Fiction (1973), de Muniz Sodré. De alinhamento marxista, Sodré vê a FC como um mito para o século XX que reforçará a ideologia capitalista dominante, conclusões vistas por seus colegas como drásticas tendo em vista o universo limitado de obras abordadas em seu trabalho. Já José Paulo Paes, em A aventura literária: ensaios sobre ficção e ficções (1990), é menos hostil ao gênero, mas não deixa de expor certa hierarquização ao ver a literatura de entretenimento como um degrau para se atingir uma suposta alta literatura.

É somente nos anos 2000 que Causo identifica o boom das pesquisas acadêmicas nacionais, destacando como uma das primeiras obras desse novo momento Viagem às letras do futuro: 
extratos de bordo da ficção científica brasileira: 1947-1975 (2002), de Francisco Alberto Skorupa, que faz um balanço da produção crítica do gênero no Brasil e chega a rever algumas injustiças ao gênero cometidas por Sodré. Além dele, Causo menciona mais de vinte teses e dissertações produzidas em um período de apenas dez anos, mostrando como, a partir dos anos 2000, a FC parece progressivamente ganhar espaço.

Em um dos maiores artigos do livro, Causo faz uma profunda retrospectiva da crítica literária sobre a FC no Brasil, não apenas elencando obras importantes, mas analisando sua pertinência dentro do cenário brasileiro e fornecendo aos interessados uma rica fonte bibliográfica para futuras pesquisas.

Dando continuidade ao diálogo próximo entre os pesquisadores da FC no Brasil, M. Elisabeth Ginway, já citada por Causo, é autora do artigo "Eugenia, a mulher e a política na literatura utópica brasileira (1909-1929)". Nele, Giway analisa como o papel da mulher varia em quatro utopias brasileiras e uma sátira distópica: São Paulo no Anno 2000 (1909), de Godofredo Emerson Barnsley; O reino de Kiato (no paiz da verdade) (1922), de Rodolpho Theophilo; $O$ presidente negro ou $O$ choque das raças (1926), de Monteiro Lobato); Sua Excia. a presidente do anno 2500 (1929), de Adalzira Bittencourt; e Virgindade inútil: novela de uma revoltada (1927), de Ercília Nogueira Cobra. Enquanto as quatro primeiras representam utopias conservadoras, seguindo ideais eugenistas neo-lamarckianos ou mendelianos, e em alguns casos racistas, a obra de Cobra serve de contraponto às demais, opondo-se de forma radical aos aspectos tomados como positivos pelas obras anteriores. 
Surgindo no período da primeira república (1889-1929), esse surto de utopias é visto por Ginway como resposta a um período de instabilidade política e econômica que vê na eugenia uma solução eficaz para o problema da sociedade. Ainda que as quatro utopias chancelem um ideal eugênico, Giwnay ressalta que há uma diferença nas abordagens: de um lado, a obra de Barnsley e Theophilo seguirão uma orientação neo-lamarckiana, que preza pelo saneamento e pela higiene, do outro, Bittencourt e Lobato seguirão uma vertente mendeliana, focando-se na questão genética e hereditária. Ginway aponta, ainda, que em cada uma dessas escolas acabará representando a mulher de uma forma diferente.

Segundo a autora, tanto em São Paulo no Anno 2000 quanto em $O$ reino de Kiato (no paiz da verdade), a mulher assume integralmente o papel de mãe, sendo até mesmo afastada dos demais afazeres e comemorações após o casamento. Já no caso de Sua Excia. a presidente do anno 2500 e 0 presidente negro ou 0 choque das raças, vê-se a mulher num papel ativo, em ambos os casos na própria presidência. É através do papel político que representam que se dará o discurso eugenista, com a castração de deficientes, expulsão de negros do país e até execução daqueles que quebrarem as medidas eugênicas impostas.

Já a obra Virgindade inútil: novela de uma revoltada, situada em Bocolândia, terra imaginária controlada pelos homens, em que a mulher deve ser subjugada ao papel da maternidade, a protagonista infringe todas as regras, de perder sua virgindade antes de casar até virar prostituta e mãe solteira. Comparando a obra de Cobra com as demais, Ginsway aponta o caráter transgressor desta e traz 
uma voz dissonante a um conservadorismo literário imperante nas utopias do começo do século XX.

Saindo da literatura brasileira para a produção de nossos vizinhos argentinos, Carlos Abraham traz o peculiar caso de uma escritora quase desconhecida do final do século XIX, em "Raimunda Torres y Quiroga: precursora do fantástico argentino".

Segundo Abraham, o caso começa com a publicação de uma série de contos fantásticos e de horror com influências de Poe, Hoffman e Shakespeare em diversos periódicos de Buenos Aires. Assinando Matilde Elena Wuili, a misteriosa autora manteve sigilo sobre sua real identidade, descoberta apenas com a publicação da compilação de seus textos, sob o título de Entretenimientos literarios, em 1884.

Através de uma dedução de obras anteriormente publicadas em periódicos, chega-se ao nome de Raimunda Torres y Quiroga. Descobre-se, ainda, que a autora, tal qual Pessoa, utilizava heterônimos distintos para cada um dos seus estilos de escrita, fato incomum na literatura argentina.

Das quatro partes em que o livro se divide, apenas uma é dedicada aos contos fantásticos da autora, parte essa em que Abraham se aprofunda, resenhando cada um dos textos encontrados no livro. Ao longo de sua descrição, é possível perceber certas recorrências temáticas da autora. Na maior parte de suas narrativas, há a presença de espectros ou esqueletos, em atmosfera noturna e frequentemente marcada por tempestades fortes. $\mathrm{O}$ assassinato de mulheres, principalmente esposas suspeitas de adultério é outra constante nos contos, geralmente redundando na loucura 
do marido por crises de consciência ou maldição dos espectros das mulheres mortas. Além disso, em alguns deles, é possível ver claras alegorias à natureza humana e à efemeridade da vida, além de uma forte carga moralista, explicada por Abraham pelo constante posicionamento anti-ateu encontrado em seus contos.

Se no bloco de críticas estrangeiras o cinema foi o foco na maioria dos artigos, o bloco sobre FC latino-americana dá mais destaque à literatura, reservando, no entanto, os três últimos trabalhos à nossa produção cinematográfica no gênero. No primeiro deles, "Ao sul do futuro: panorama do cinema latino-americano de ficção científica", Mariano Paz mostra uma trajetória da presença do cinema no México, no Brasil e na Argentina, apontando como a crítica até pouco tempo negligenciava a produção local em prol dos blockbusters hollywoodianos.

Paz dedica, ainda, uma parte de seu artigo para comentar detidamente uma obra de cada um dos países abordados, podendo assim aprofundar-se nas peculiaridades da produção de cada nação. A escolha desses três países, Paz ressalta, se dá, sobretudo, por um critério quantitativo: as produções de FC da Argentina, Brasil e México somadas equivalem a $90 \%$ de todos os filmes produzidos na América Latina.

Ao comparar a indústria cinematográfica de FC em cada um dos países, Paz nota uma diferença marcante entre a produção do México e a dos demais países estudados: a predominância de investidores privados produzindo filmes com o objetivo primário de gerar lucro. Dessa forma, ainda que tenham conseguido assim um volume considerável de obras, seus filmes não raramente eram 
malvistos pela crítica, tanto pelo uso de roteiros apelativos quanto pelos atores questionáveis, comediantes e lutadores famosos usados para atrair as massas. No Brasil e na Argentina, como a presença do investimento privado era baixa, cabia ao Estado o papel de alavancar o cinema nacional. No caso brasileiro, em alguns períodos de recesso, o investimento privado desviou a produção nacional para esse cinema de maior apelo popular - sobretudo nas pornochanchadas -, já a Argentina majoritariamente se manteve dentro das produções classificadas por Paz como FC especulativa ou "sério-dramática".

Para representar o cinema mexicano, Paz opta por um dos mais populares filmes envolvendo lutadores famosos, Santo vs la invasion de los marcianos, tipo de produção tão popular no México, que Paz afirma que apenas Santo, o ator principal da obra, fez mais de cinquenta filmes, a maior parte de FC e horror. No Brasil, Paz analisa o filme Parada 88: o limite de alerta (1978), de José de Anchieta. A obra narra a história de um Brasil distópico em que um acidente nuclear contamina o ar e obriga os cidadãos a comprar ar de uma empresa privada para sobreviver em uma cidade selada e interligada por túneis subterrâneos. Por último, analisa La sonámbula (1998), de Fernando Spiner, escrito pelo diretor em conjunto com Ricardo Piglia. Mantendo premissa semelhante à de Parada 88, o filme retrata uma Buenos Aires distópica cujos habitantes perdem a memória após um acidente químico e são manipulados pelo governo durante o processo de recuperação.

Da mesma forma que o artigo de Causo aprofunda o caso brasileiro já visto no panorama de Ferreira, Alfredo Suppia, organizador do livro, dá continuidade ao panorama já iniciado por 
Paz, mostrando um extensivo trabalho especificamente sobre o cinema de FC brasileiro.

Suppia trabalha, em seu histórico, com uma categorização de duas vertentes da FC na produção nacional, a "sério-dramática" e a "lúdico-carnavalesca", com uma predominância da última em boa parte da trajetória do gênero no Brasil. Vemos essa predominância já nas versões prototípicas do gênero, ainda no começo do XX, com obras como Duelo de cozinheiros e Elixir da juventude, ambos de 1908, e $O$ caso do Rio, de 1909. O mesmo vale para a obra vista como pioneira à FC de fato, Uma aventura aos 40 (1947), de Silveira Sampaio. Nos anos 60, esse panorama tampouco mudará, com uma exceção: o filme $O$ quinto poder (1962), de Alfredo Pieralisi, que abordava uma trama de invasores estrangeiros, lavagem cerebral por mensagem subliminar e golpe militar.

Nos anos 70, com influência do cinema novo, que no final dos 60 dialogou com a FC, mostrando sua capacidade alegórica e de crítica social, houve um fortalecimento dos filmes sério-dramáticos. Suppia prossegue, assim, apresentando obras marcantes da época, como $O$ anunciador: o homem das tormentas (1970), de Paulo Bastos Martins, O homem das estrelas (1971), de Jean-Daniel Pollet, a ficção psico-científica O macabro Dr. Scivano (1971), de Raul Calhado e Rosalvo Caçador, e Quem é beta (1972-73), de Nelson Pereira dos Santos. A vertente lúdico-carnavalesca, no entanto, não sai de cena, aparecendo em pastiches da FC estrangeira em alguns filmes dos Trapalhões, por exemplo. A década é, ainda, marcada pelo Parada 88, que, dada a importância já ressaltada por Mariano Paz, é alvo de uma análise aprofundada de elaboração e produção por parte de Suppia. 
Na década de 80, Suppia aponta a continuidade de uma versão mais cômica da FC nas pornochanchadas e no "terrir", mas dá destaque a obras que mantêm o padrão sério-dramático, como a ecodistopia Abrigo nuclear (1981), de Roberto Pires, que segue - padrão de Parada 88 na crítica contundente aos problemas da poluição, e o curioso Amor voraz (1984), de Walter Hugo Khouri, uma intimista história de FC quase ausente de elementos que marcam o gênero, narrando uma história de amor entre uma mulher e um alienígena.

Suppia ressalta que a década de 90 sofreu um declínio de produção, mostrando apenas alguns casos isolados. Um dos mais promissores, Oceano Atlantis, de Francisco de Paula, rodado entre 1989 e 1993, ecodistopia que daria continuidade à temática ambiental encontrada em Parada 88 e Abrigo Nuclear, jamais foi lançado comercialmente. Já nos anos 2000, temos a tentativa de Acquaria (2004), de Flávia Moraes, unindo a temática do apocalipse ambiental ao público jovem, com Sandy e Júnior como protagonistas. Suppia também destaca o metacinema de Saneamento básico, o filme (2007), de Jorge Furtado, que dialoga com as dificuldades encontradas na produção de filmes em território nacional. Por último, menciona a curiosa união entre FC e espiritismo de Nosso Lar (2010), de Wagner de Assis, intuindo nele uma possível tendência para o cinema de FC contemporâneo.

Suppia encerra seu artigo de forma otimista, entendendo que apesar dessa atmosfera rarefeita do cinema brasileiro de FC, em que problemas políticos, econômicos e a própria reação da crítica e do público dificultam o avanço do gênero, não impede o florescimento de dezenas de obras nacionais de qualidade, que dialogam com 
seus momentos políticos e oferecem ferramentas para se pensar a cultura nacional.

Se, diferente de Mariano Paz, Suppia não se dedica a análises aprofundadas de algumas obras, o artigo final do livro, "Horror, ficção científica e tecnologia da informação em três filmes brasileiros", de Laura Loguercio Cánepa, serve perfeitamente de complemento ao panorama de Suppia, abordando, como no caso de Paz, três produções cinematográficas nacionais: O signo de escorpião (1974), de Carlos Coimbra; Excitação (1976), de Jean Garrett; e As filhas do fogo (1978), de Walter Hugo Khouri. A escolha de Cánepa se dá por uma temática peculiar na qual o misticismo de vidas passadas e maldições ancestrais se une ao imaginário tecnológico num misto de horror e FC.

Os três filmes analisados por Cánepa surgem no contexto das pornochanchadas dos anos 70, em que os produtores se aproveitavam da temática erótica e de enredos apelativos para atrair a atenção de seus espectadores, filmando obras que muitas vezes reciclavam temáticas ou histórias populares no exterior.

Em O signo de Escorpião, primeiro filme abordado pela autora, a história gira em torno de uma série de assassinatos misteriosos no estilo de Agatha Christie, em que um computador capaz de ler o signo das pessoas prenuncia a morte de cada um dos participantes envolvidos no teste da máquina, que é operada telepaticamente por membros de uma seita secreta. Já em Excitação, melhor sucedido que seu antecessor, vemos a história de uma mulher com problemas psicológicos que é deixada sozinha em uma casa de praia e passa a ser atacada pelos eletrodomésticos, controlados a distância pelo marido que desejava enlouquecê-la para roubar sua 
fortuna. No entanto, o espírito de um homem que se enforcou na casa ajuda a mulher a se vingar do marido. Por último, As filhas do fogo, mais enigmático que os outros dois, é fruto do imaginário de Khouri, influenciado desde novo por nomes como Poe, Henry James e Lovecraft. O filme envolve duas amigas convivendo em uma mansão em que a mãe de uma das duas havia morrido e, em seu decorrer, expõe as meninas a uma série de acontecimentos paranormais que culminam na morte de uma delas.

A autora conclui assim mostrando como mesmo dentro de um nicho que carecia de total legitimidade, é possível ver uma produção cinematográfica significativa para a FC no Brasil, abordando não apenas a fusão de gêneros populares de entretenimento como também mostrando uma característica que viria a ganhar força posteriormente, como já mostrou Suppia: a intersecção entre a FC e o misticismo.

Contando com quinze artigos de objetivos, temas e abordagens bem variados, mas todos de grande valor para os estudiosos de FC, cinema, horror e literaturas que dialogam com o insólito, Cartografias para a ficção científica mundial consegue concretizar seu objetivo: preenche um pouco desse vácuo de teoria e crítica no gênero, não só em língua portuguesa, como também sobre as próprias produções brasileiras. Seja para conhecer obras encobertas pela distância temporal e/ou espacial, para conhecer mais a fundo as vertentes do gênero ou para melhor entender o funcionamento dos efeitos estéticos causados por suas obras, Cartografias merece um espaço de destaque na estante dos estudos de FC no Brasil. 